\title{
COPPER AND ZINC LEVELS IN HAIR OF BOTH SCHIZOPHRENIC AND DEPRESSED PATIENTS
}

\author{
BY \\ Abd-Elaziz A. Ghanem, Essam M. Ali, Amal A. El-Bakary, Doaa A. El-Morsy, \\ Sherif M.H. Elkanishi*, El-Sayed Saleh* and Hanan El-Said ** \\ Department of Forensic Medicine and Clinical Toxicology, Analytical Toxicology Unit, Emergency Hospital*, \\ Department of Psychiatry** - Faculty of Medicine, Mansoura University
}

\begin{abstract}
The aim of this paper is to estimate hair copper and zinc levels in schizophrenic and depressed patients and to correlate these levels to the severity of schizophrenia and major depressive disorder. The study was carried on 80 male and female persons with their ages between $20-40$ years. Twenty of them were healthy and helped as control, 30 were suffering from schizophrenia (group I) and 30 were suffering from major depressive disorder (group II). Exclusion criteria included pregnancy, another co-morbid psychiatric disorders and drugs known to affect trace element metabolism. Approximately $100 \mathrm{mg}$ of scalp hair samples were cut from each person. Zinc and copper levels in the hair samples were determined by atomic absorption spectrophotometry after wet ashing. The mean hair copper level was significantly higher in both schizophrenic patients (group I) and depressed patients (group II) when compared with their corresponding mean level in healthy control group. On the other hand, the mean hair zinc level was significantly lower in both schizophrenic patients (group I) and depressed patients (group II) when compared with its mean level in the healthy control group. In depressed patients, the mean hair copper level was insignificantly higher while, the mean hair zinc level was significantly lower when compared with their corresponding mean level in schizophrenic patients. From these results, it can be concluded that copper excess and zinc deficiency may have a role in the pathogenesis of either schizophrenia and/ or depressive disorders. It can also be concluded that zinc deficiency may have more important role in inducing depressive disorders. So, it is recommended to evaluate both copper and zinc hair and serum levels in schizophrenic and depressed patients especially in those resistant to the traditional therapy measures. Moreover, this may have a prognostic value. It is recommended also to use zinc supplementation during antidepressant therapy as it may improve response to therapy and/ or decrease the antidepressant dose that can minimize the side effects.
\end{abstract}

\section{INTRODUCTION}

Copper $(\mathrm{Cu})$ and zinc $(\mathrm{Zn})$ are two essential trace elements that have been studied in many diseases, including autoimmune, neurologic and psychiatric disor- 
ders (Cramer, 1983). Whenever zinc becomes deficient, copper tends to accumulate (Yanik et al., 2004).

Copper is a component of several metalloenzymes linked to dopamine synthesis, in biochemical pathways involving either antagonism of dopamine production or catalysis of its breakdown. As dopamine is implicated in schizophrenia, copper homeostasis may be particularly relevant: an excess of copper may be associated with dopamine dys-regulation (Bowman and Lewis, 1982). Zinc is required for the structural integrity and/or catalysis of more than 200 enzymes, the majority of which are zinc metalloenzymes involved in nucleic acid and protein synthesis (Abdel-Mageed and Oehme, 1990).

The findings of previous research on the status of trace elements in patients with schizophrenia have been controversial (Herrán et al., 2000). Some authors did not find significant deviation from normal in concentrations of serum copper (Gillin et al., 1982) or found a decrease in hair copper concentrations in chronic schizophrenic females (Suzuki et al., 1992). Others demonstrated significant increase in the serum and hair concentration of $\mathrm{Cu}$ and significant decrease in $\mathrm{Zn}$ in schizophrenic patients than that of their levels in the control group (Tokedemir et al., 2003; Wolf et al., 2006; Rahman et al., 2009).
It was found also that major depressed subjects had significantly lower serum zinc concentrations than normal controls and that clinical improvement was accompanied by increments in serum zinc (McLoughlin and Hodge, 1990). Meanwhile, copper levels and $\mathrm{Cu} / \mathrm{Zn}$ ratios were significantly higher in women having a history of post-partum depression (Crayton and Walsh, 2007).

This study was undertaken to estimate hair copper and zinc levels in schizophrenics and patients with depression to declare their possible role in the pathogenesis of these disorders. Also, whether the levels of these trace elements could be correlated to the severity of schizophrenic and depressive disorders would be studied.

\section{SUBJECTS AND METHODS}

\section{Subjects:}

The present study was carried on 80 male and female persons; 20 of them (10 males and 10 females) were clinically and laboratory healthy and helped as control, 30 (15 males and 15 females) were suffering from schizophrenia (group I) and 30 (15 males and 15 females) were suffering from major depression (group II). The age of all persons of the study is between 20 40 years with mean age $30.1 \pm 5.6 \mathrm{y}$ in control group, $30.26 \pm 5.63 \mathrm{y}$ in group I and $30.63 \pm 5.54 \mathrm{y}$ in group II. Exclusion 
criteria for all persons selected for the study included another co-morbid psychiatric disorder, pregnancy and medical disorders (endocrine, liver cirrhosis, renal insufficiency) or intake of certain drugs (as anticonvulsants, contra-ceptives, glucocorticoids) known to affect trace element metabolism. These criteria were determined according to study of Farzin et al. (2006). The exclusion was done through history taking and routine laboratory investigations.

Patients were recruited from Psychiatry Department of Mansoura University Hospital. Assessment and diagnosis of schizophrenic and depressed patients were made according to the Diagnostic and Statistical Manual of mental disorders $\left(4^{\text {th }}\right.$ division Text Revised) DSM IV TR criteria. Positive and negative syndrome scale (PANSS) for schizophrenia (Kay et al., 1987) was used as adjunct to the positivenegative symptoms assessment to provide a parallel measure of severity of schizophrenic illness. The score based on General Psychopathology Scale (ranged from 16 - 112) was used for testing of statistical correlation between severity of schizophrenic illness and zinc and copper levels in hair. Assessment of the severity of depression was made according to translated self-report rating inventory which was developed by Beck et al., (1961) that measure characteristic attitudes and symptoms of depression and its severity.

\section{Samples collection:}

Approximately $100 \mathrm{mg}$ of scalp hair samples were cut from each person with stainless-steel scissors in the nape or occipital regions, as close to the scalp as possible. Hair collection was carried out in dust-free environment and hair treated with artificial color was excluded from the study. The distal ends of the hair were cut from the samples. Each hair sample was comminuted, washed consecutively in neutral detergent as ether and acetone and dried before analysis according to the procedure originally described by Sorenson, et al. (1973).

\section{Biochemical studies:}

Zinc and copper levels in hair samples were determined by atomic absorption spectrophotometry after wet ashing using reagent-grade $\mathrm{HNO}_{3}$ and $\mathrm{HClO}_{4}$ according to Eads and Lambdin (1973). For analysis the Model Varian Spectra AA 400, atomic absorption spectrophotometer was used. Atomization signals were recorded from the digital readout. The light sources were zinc and copper hollowcathode lamps. Uncoated graphite tubes (Varian 63 - 100015 - 00) were used for furnace. Wavelengths were set at 324.8 and $213.9 \mathrm{~nm}$ for copper and zinc respectively.

\section{Statistical analysis:}

Statistical analysis was done by using the Statistical Package for Social Science (SPSS) program version 12 . The following 
statistical parameters were utilized: arithmetic mean $(x)$, standard deviation $( \pm S D)$, Student t-test and correlation coefficient. Significance was considered at $\mathrm{P}$ value less than 0.05 .

\section{RESULTS}

The mean hair copper levels are 29.8 $\mathrm{ug} / \mathrm{mg} \pm 5.46$ in control group, 46.82 $\mathrm{ug} / \mathrm{mg} \pm 9.66$ in schizophrenic patients (group I) and $48.6 \mathrm{ug} / \mathrm{mg} \pm 15.75 \mathrm{in}$ depressed patients (group II). The mean hair zinc levels are $488.23 \mathrm{ug} / \mathrm{mg} \pm 6.56 \mathrm{in}$ control group, $421.08 \mathrm{ug} / \mathrm{mg} \pm 54.7 \mathrm{in}$ schizophrenic patients (group I) and $381.47 \mathrm{ug} / \mathrm{mg} \pm 70.75$ in depressed patients (group II) (Table 1).

The mean hair copper level is significantly higher in both schizophrenic patients (group I) and depressed patients (group II) when compared with its mean levels in healthy control group. In depressed patients the mean hair copper level is insignificantly higher when compared with its mean level in schizophrenic patients (Table 1).

The mean hair zinc level is significantly lower in both schizophrenic patients (group I) and depressed patients (group II) when compared with its mean levels in healthy control group. In depressed patients the mean hair zinc level is significantly lower when compared with its mean level in schizophrenic patients (Table 1).

Results of the present study show significant positive correlation between hair copper level and the severity of illness in schizophrenics and depressed patients. On the other hand, significant negative correlation is found between hair zinc level and the severity of illness in the same cases (Table 2 and Figures 1 - 4).

The percentage of increase of mean hair copper level is more in depressed patients than that in schizophrenic patients (Figure 5). The percentage of decrease of mean hair zinc level is more in depressed patients than that in schizophrenic patients (Figure 6).

\section{DISCUSSION}

Deficiency as well as excess in either zinc or copper can produce a variety of biochemical and physiologic changes (Jun and Nancy, 2000). In addition, these two essential trace elements are neuroactive substances that can be synaptically released during neuronal activity. They have been implicated in diseases with neuropathological components (Strausak et al., 2001).

Previous observations suggested that there may be an association between elevated serum and hair $\mathrm{Cu}$ levels and 
decreased serum and hair $\mathrm{Zn}$ levels and some psychiatric disorders. A relation between low concentrations of zinc and mental health problems, especially in atrisk populations has been demonstrated. Zinc deficiency induced depression-like behavior in mice that was incompletely corrected by antidepressant therapy (Whittle et al., 2009).

The results of the present work showed significant increase in the mean hair copper level and significant decrease in the mean hair zinc level in schizophrenic patients compared with their corresponding mean levels in healthy control group.

Similar results were found in the study of Rahman et al. (2009). Another earlier study found that serum copper and ceruloplasmin were elevated in schizophrenia (Wolf et al., 2006). Nechifor et al. (2004) observed also that $\mathrm{Cu} / \mathrm{Zn}$ ratios were increased in patients with acute paranoid schizophrenia episode. In addition, they found that $\mathrm{Zn}$ levels but not plasma $\mathrm{Cu}$ was found to improve after 3 weeks of antipsychotic treatment. In criminal schizophrenic subjects, Tokedemir et al. (2003) found that serum copper values were significantly higher while zinc values were significantly lower than non-criminal subjects.

In disagreement of the present results, the study of Gillin et al. (1982), who found that patients with acute and chronic schizophrenia, on or off treatment with various major tranquillizers, did not show any significant deviation from normal in concentrations of zinc or copper in serum, urine, or gastric fluid, in serum ceruloplasmin or in hair zinc. Suzuki et al. (1992) found also a decrease in hair copper concentrations in chronic schizophrenic females. Nechifor et al. (2004) explained this heterogeneity of the data by heterogeneity of patients and presence of many forms of schizophrenia.

The role of copper and ceruloplasmin in schizophrenia remains unclear. Although elevation of copper and ceruloplasmin may be related to other factors and are insufficient alone to infer pathogenic causality, copper abnormalities may play a role in schizophrenia by exacerbating or perpetuating dopaminergic dysregulation (Bowman and Lewis, 1982). However it is unknown at this stage whether the copper contributes to the mental illness or the body attempts to store more copper in response to the illness. Herrán et al. (2000) postulated that elevated $\mathrm{Cu}$ levels may be a consequence of antipsychotic treatment which may affect absorption, plasma protein binding, storage and / or excretion of these metals (Rand and Murray, 2000). Contradictory to this postulation, Gillin et al. (1982) concluded that patients on various major tranquillizers did not show any significant deviation from normal in concentrations of zinc or copper. 
The results of the present work showed also significant increase in the mean hair copper level and significant decrease in the mean hair zinc level in depressed patients compared with their mean levels in healthy control group. In addition, zinc levels were significantly lower in depressed patients compared to schizophrenic patients. Similarly, Manser, et al. (1989) and Narang, et al. (1991) found that $\mathrm{Cu}$ levels were significantly higher in depressives than in the normal and after recovery from depression. Others found that major depressed subjects had significantly lower serum zinc concentrations than normal controls (McLoughlin and Hodge, 1990). Even lower serum Zn was considered a marker of treatment resistance and of the immune/inflammatory response in depression (Maes et al., 1997). Also, copper levels and $\mathrm{Cu} / \mathrm{Zn}$ ratios were significantly higher in women having a history of post-partum depression (Crayton and Walsh, 2007).

Changes in plasma $\mathrm{Cu}$ and $\mathrm{Zn}$ contents can cause health problems because they can oxidize proteins and lipids, bind to nucleic acid and enhance the production of free radicals (Rand and Murray, 2000). Copper/zinc superoxide dismutase coenzyme concentrations in postmortem prefrontal cortical regions of the brain was significantly increased in patients with recurrent depressive disorder evidencing oxidative stress in the pathophysiology of depressive disorder (Michel et al., 2007).

The significant negative correlation that was found in the present work between hair zinc level and the severity of both schizophrenic illness and depression support the study of Pfeiffer and Braverman (1982) who stated that zinc has been employed with success to treat specific types of schizophrenia. These coincide also with McLoughlin and Hodge (1990) who found that clinical improvement of major depressed subjects was accompanied by increments in serum zinc. However, Maes et al. (1997) concluded that, there were no significant effects of antidepressant treatment on serum $\mathrm{Zn}$, whereas serum $\mathrm{Cu}$ was significantly reduced.

The clinical efficacy of current antidepressant therapies is unsatisfactory; antidepressants induce a variety of unwanted effects, and, moreover, their therapeutic mechanism is not clearly understood (Szewczyk et al., 2008). Zinc and magnesium exhibit antidepressant activity in laboratory animals. The efficacy of pharmacotherapy is enhanced by supplementation with zinc and magnesium particularly in patients previously nonresponsive to antidepressant pharmacotherapies (Cunha et al., 2008 and Siwek et al., 2009).

From the results of the present work, it can be concluded that copper excess and 
zinc deficiency may have a role in pathogenesis of both schizophrenia and depressive disorders. It can also be concluded that zinc deficiency has more important role in inducing depressive disorders.

It is recommended to evaluate both copper and zinc hair and serum levels in schizophrenic and depressed patients especially in patients resistant to therapy as this may have a prognostic value. It is rec- ommended also to use zinc supplementation during antidepressant therapy as it may improve response to therapy and / or decrease the dose that can minimize the side effects of antidepressants. Frequent psychiatric assessment is recommended for individuals chronically exposed to cupper. Zinc rich food as meat is advised to minimize liability to develop depressive disorders. Zinc supplementation is recommended especially in resistant cases. 
Table (1): Comparison between mean hair copper and zinc levels (ug/mg) in all groups of the study.

\begin{tabular}{|c|c|c|c|c|}
\hline \multicolumn{2}{|c|}{ Parameters } & Control Group & Group (I) & Group (II) \\
\hline \multirow{5}{*}{$\begin{array}{l}\text { Hair } \\
\text { copper } \\
\text { level } \\
(\mathrm{ug} / \mathrm{mg})\end{array}$} & Mean \pm SD & $29.8 \pm 5.46$ & $46.82 \pm 9.66$ & $48.6 \pm \quad 15.75$ \\
\hline & \multirow[t]{2}{*}{ 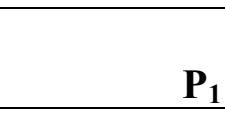 } & & \& & \& \\
\hline & & & $<0.001 *$ & $<0.001^{*}$ \\
\hline & \multirow[b]{2}{*}{$\mathbf{P}_{2}$} & & & \& \\
\hline & & & & 0.638 \\
\hline \multirow{5}{*}{$\begin{array}{l}\text { Hair } \\
\text { zinc } \\
\text { level } \\
\text { (ug/mg) }\end{array}$} & Mean \pm SD & $488.23 \pm 6.56$ & $421.08 \pm 54.7$ & $381.47 \pm 70.75$ \\
\hline & \multirow{3}{*}{$\mathbf{P}_{1}$} & & Gor & Go \\
\hline & & & $<0.001 *$ & $<0.001 *$ \\
\hline & & & & Gor \\
\hline & $\mathbf{P}_{2}$ & & & $<0.05^{*}$ \\
\hline
\end{tabular}

* Significant if $\mathrm{P}<0.05$, \& $=$ higher, $6 \mathbf{\sigma}=$ lower, Group I: Schizophrenic patients, Group II: Depressed patients, $\mathrm{P}_{1}$ : Schizophrenics and depressed patients versus control and $\mathrm{P}_{2}$ : Depressed patients versus Schizophrenics.

Table (2): Correlation between hair copper and zinc levels and severity of schizophrenic symptoms assessed by PANSS and severity of depressive symptoms assessed by Beck score.

\begin{tabular}{|c|c|c|c|}
\hline & & Hair copper level & Hair zinc level \\
\hline \multirow{3}{*}{$\begin{array}{c}\text { PANSS } \\
\text { (for schizophrenia) }\end{array}$} & $\mathrm{r}$ & 0.984 & 0.943 \\
\hline & $\mathrm{P}$ & $0.000 *$ & $0.000 *$ \\
\hline & $\mathrm{n}$ & 30 & 30 \\
\hline \multirow{3}{*}{$\begin{array}{c}\text { Beck score } \\
\text { (Depression severity) }\end{array}$} & $\mathrm{r}$ & 0.994 & 0.973 \\
\hline & $\mathrm{P}$ & $0.000 *$ & $0.000 *$ \\
\hline & $\mathrm{n}$ & 30 & 30 \\
\hline
\end{tabular}

${ }^{*}$ Correlation is significant at 0.01 level (2-tailed) 


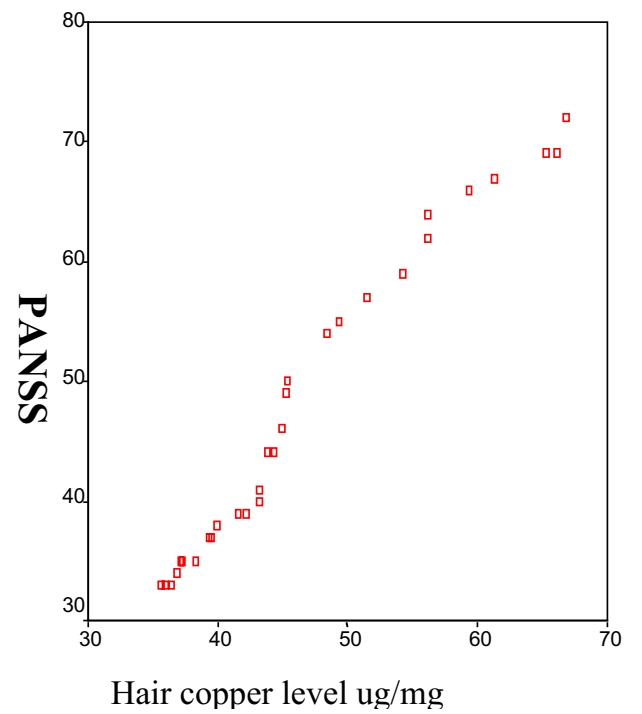

Fig. (1) : The statistical correlation between hair copper level and severity of schizophrenic symptoms assessed by PANSS.

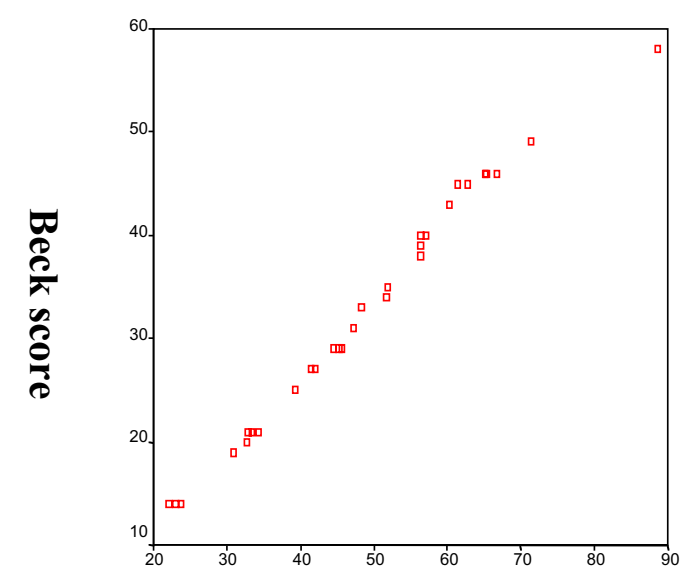

Hair copper level ug/mg

Fig. (3) : The statistical correlation between hair copper level and severity of depressive symptoms assessed by Beck score.

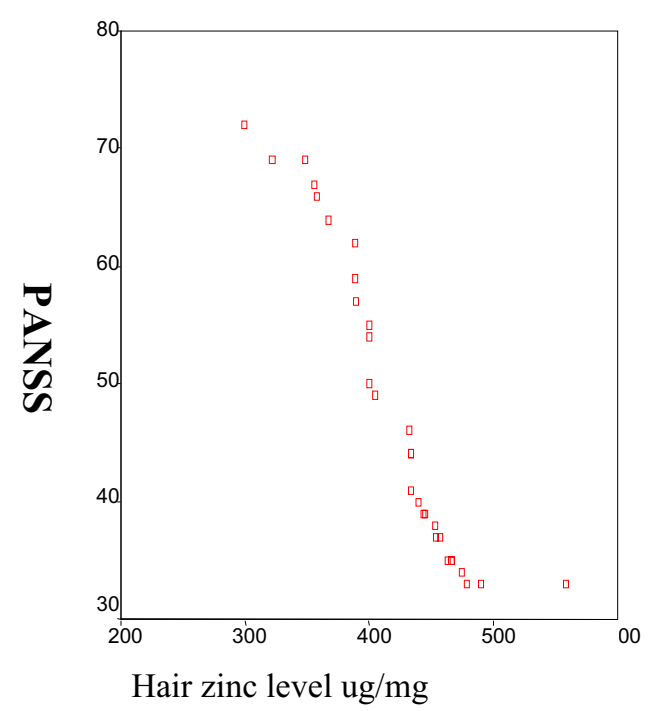

Fig. (2) : The statistical correlation between hair zinc level and severity of schizophrenic symptoms assessed by PANSS.

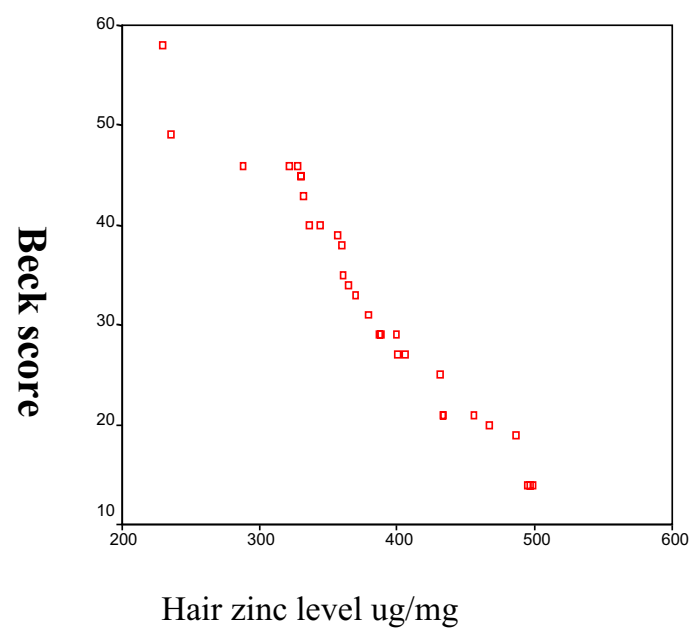

Fig. (4) : The statistical correlation between hair zinc level and severity of depressive symptoms assessed by Beck score. 


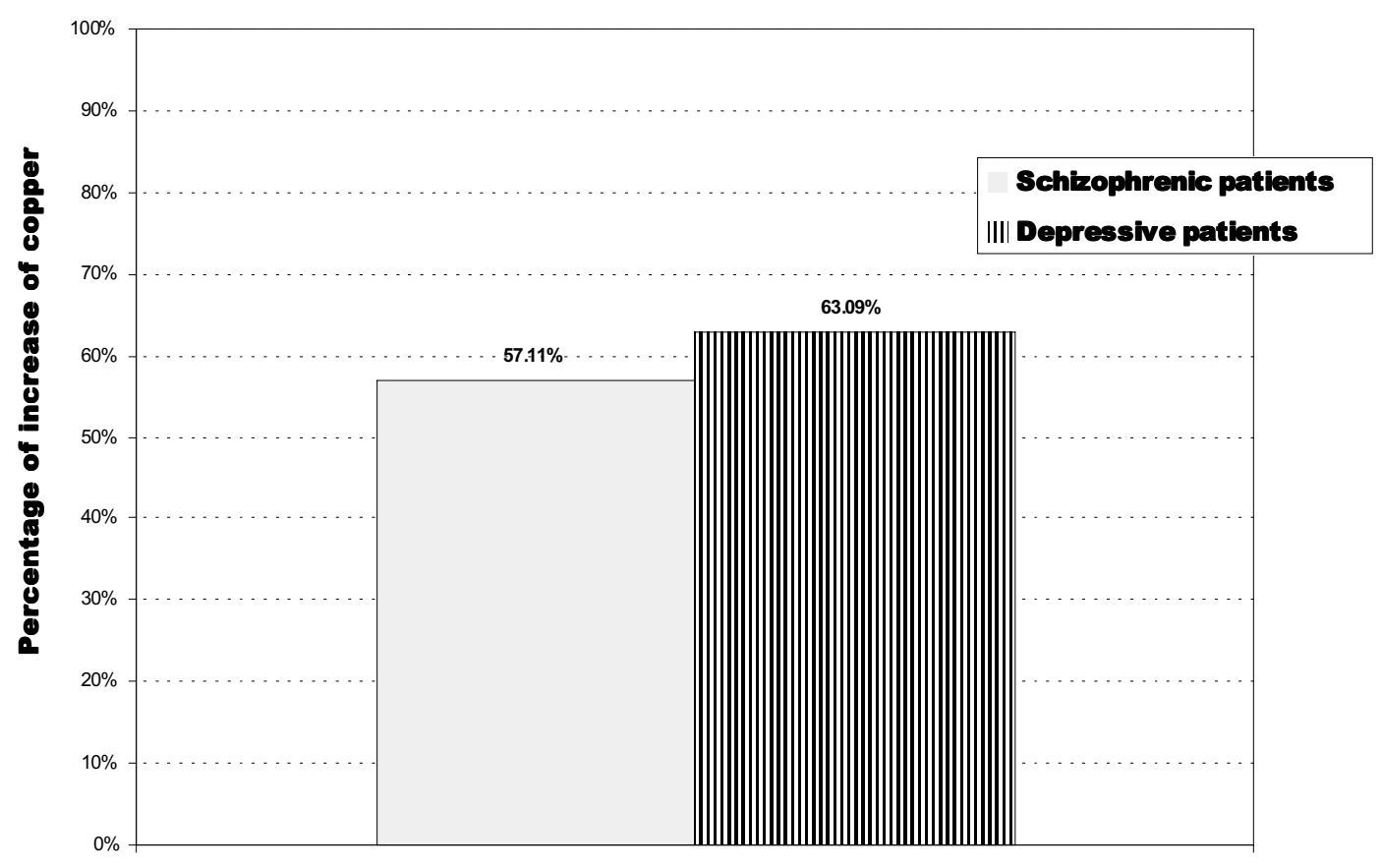

Fig. (5) : Percentage of increase in mean hair copper level in both schizophrenic and depressed patients.

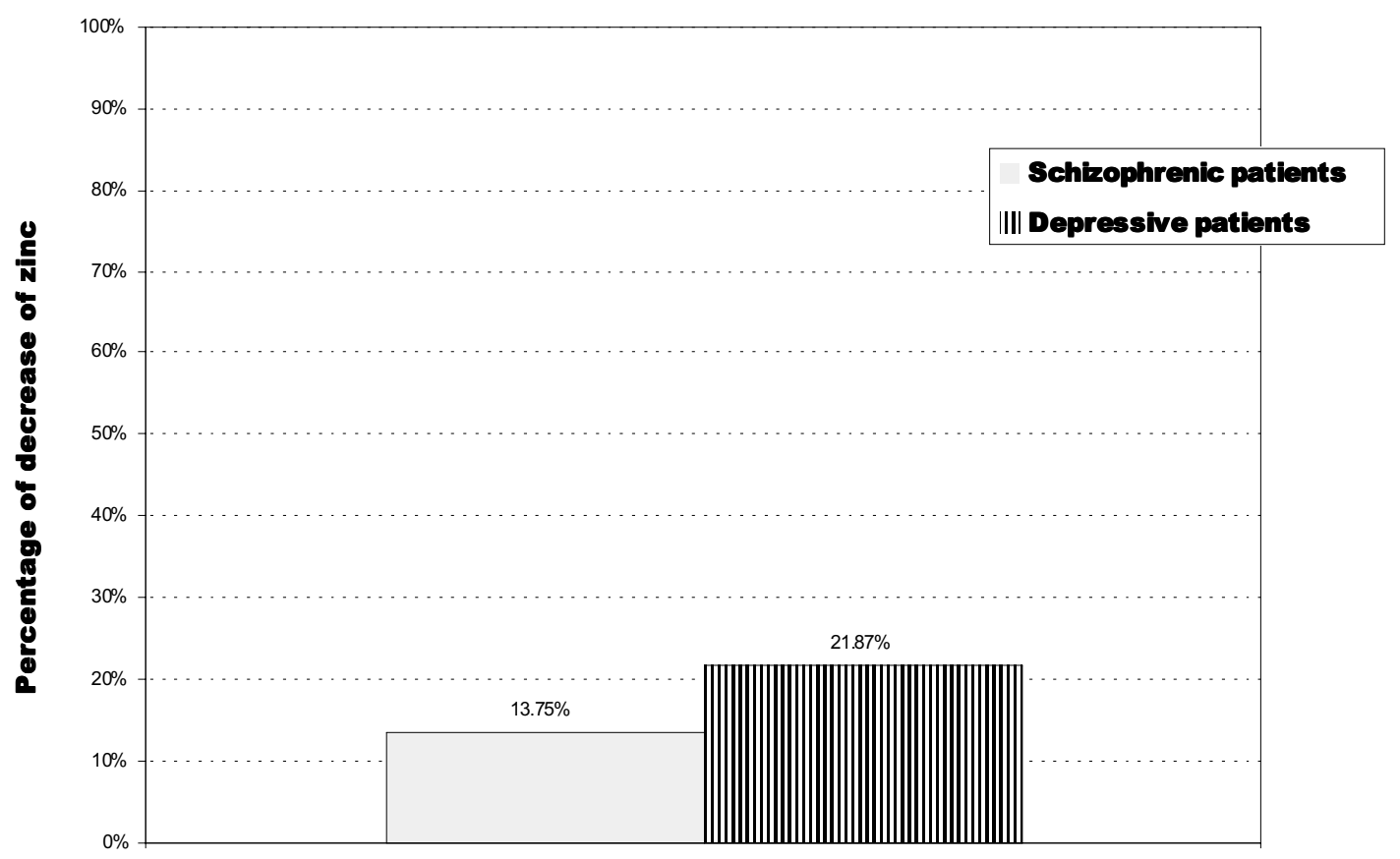

Fig. (6) : Percentage of decrease in mean hair zinc level in both schizophrenic and depressed patients. 


\section{REFERENCES}

Abdel-Mageed, A. and Oehme, F. (1990): "A review of the biochemical roles, toxicity and interactions of zinc, copper and iron: I. Zinc". Vet. Hum. Toxicol., 32:34-39.

Beck, A.; Ward, C.; Mendelson, M.; et al. (1961) : "An Inventory for Measuring Depression". Arch. Gen. Psychiatry, 4 (6):561-571.

Bowman, M. and Lewis, M. (1982) : "The copper hypothesis of schizophrenia: A review". Neurosci. Biobehav. Rev., (6): 321-328.

Cramer, J. (1983) : "Trace elements in neuropsychiatry". British J. Psychiatry, 143: 85-88.

Crayton, J. and Walsh, W. (2007) : "Elevated serum copper levels in women with a history of post-partum depression". J. Trace Elem. Med. and Biol., 21(14): 17-21.

Cunha, M.; Machado, D.; Bettio, L.; et al. (2008) : "Interaction of zinc with antidepressants in the tail suspension test". Prog. Neuropsychopharmacol. Biol. Psychiatry, 32 (8): 1913-1920.

Eads, E. and Lambdin, C. (1973) : "A survey of trace metals in human hair". Environ. Res., 6: 247-252.
Farzin, D.; Mansouri, N. and Yazdani, T. (2006) : "Elevated plasma copper/zinc ratios in patients with schizophrenia". Europ. Neuropsychopharmacol., 16, (Supplement 4): S364-S365.

Gillin, J.; Carpenter, W.; Hambidge, K.; et al. (1982) : "Zinc and copper in patients with schizophrenia". Encephale., 8 (3): 435-444.

Herrán, A.; García-Unzueta, M.; Fernández-González, M.; et al. (2000) : "Higher levels of serum copper in schizophrenic patients treated with depot neuroleptics". Psychiat. Res., 94(1):51-58.

Jun, M. and Nancy, M. (2000) : "Zinc and copper intakes and their major food sources for older adults in the 1994-96 continuing survey of food intakes by individuals (CSFII) ". J. Nut., 130: 2838- 2843.

Kay, S.; Fiszbein, A. and Opler, L. (1987) : "The positive and negative syndrome scale (PANSS) for schizophrenia". Schizophr. Bull., 13(2): 261-276.

Maes, M.; Vandoolaeghe, E.; Neels, H.; et al. (1997) : "Lower serum zinc in major depression is a sensitive marker of treatment resistance and of the immune/ inflammatory response in that illness". Biol. Psychiatry, 42 (5): 349- 358.

Manser, W.; Khan, M. and Hasan, K. 
(1989) : "Trace element studies on Karachi population. Part IV: Blood copper, zinc, magnesium and lead levels in psychiatric patients with depression, mental retardation and seizure disorders". J. Pak. Med. Assoc., 39 (10): 269-274.

McLoughlin, I. and Hodge, J. (1990) : "Zinc in depressive disorder". Acta Psychiatr. Scand., 82: 451- 453.

Michel, T.; Frangou, S., Thiemeyer, D.; et al. (2007) : "Evidence for oxidative stress in the frontal cortex in patients with recurrent depressive disorder--a postmortem study". Psychiatry Res., 151(1-2):145-150.

Narang, R.; Gupta, K.; Narang, A.; et al. (1991) : "Levels of copper and zinc in depression". Indian J. Physiol. Pharmacol., 35 (4):272-274.

Nechifor, M.; Vaideanu, C.; Palamaru, L.; et al. (2004) : "The influence of some antipsychotics on erythrocyte magnesium and plasma magnesium, calcium, copper and zinc in patients with paranoid schizophrenia". J. Am. College Nut., 23 (5): 549S$551 S$.

Pfeiffer, C. and Braverman, E. (1982) : "Zinc, the brain and behavior". Biol. Psychiatry, 17(4): 513-532.

Rahman, A.; Azad, M.; Hossain, I.; et al. (2009) : "Zinc, manganese, calcium, copper, and cadmium level in scalp hair samples of schizophrenic patients". Biol. Trace Elem. Res., 127(2): 102-108.

Rand, M. and Murray, R. (2000) : Plasma proteins. immunoglobulins and blood coagulation. In : Lange Medical Book : Harper s Biochemistry. Murray, R. K.; Granner, D. K. Mayes P. A. ; Rodwell, V. W. (Eds.), Appelton and Lang, California, USA, Ch . 59, P.P.: $737-762$.

Siwek, M.; Dudek, D.; Paul, I.; et al. (2009) : "Zinc supplementation augments efficacy of imipramine in treatment resistant patients: A double blind, placebocontrolled study". J. Affect. Disord., In Press (Abstract from Pubmed).

Sorenson, J.; Merby, E.; Nord, P.; et al. (1973) : "Interferences in the determination of metallic elements in human hair". Arch. Environ. Health, 27: 36-39.

Strausak, D.; Mercer, J.; Dieter, H.; et al. (2001) : "Copper in disorders with neurological symptoms: Alzheimer's, Menkes and Wilson's diseases". Brain Res. Bul., 55: 175-185.

Suzuki, T.; Koizumi, J.; Moroji, T.; et al. (1992) : "Effects of long term anticonvulsant therapy on copper, zinc, and magnesium in air and serum of epileptics". Biol. Psychiat., 31: 571-583. 
Szewczyk, B.; Poleszak, E.; Sowa-Kuma, M.; et al. (2008) : "Antidepressant activity of zinc and magnesium in view of the current hypotheses of antidepressant action". Pharmacol. Rep., 60(5): 588-589.

Tokdemir, M.; Polat, S.; Acik, Y.; et al. (2003) : "Blood zinc and copper concentrations in criminal and noncriminal schizophrenic men". Arch. Androl., 49 (5): 365368.

Whittle, N.; Lubec, G. and Singewald, N. (2009) : "Zinc deficiency induces enhanced depression-like behaviour and al- tered limbic activation reversed by antidepressant treatment in mice". Amino Acids; 36 (1):147-158.

Wolf, T.; Kotun, B. and MeadorWoodruff, J. (2006) : "Plasma copper, iron, ceruloplasmin and ferroxidase activity in schizophrenia". Schiz. Res., 86 (1-3): 167171.

Yanik, M.; Kocyigit, A.; Tutkun, H.; et al. (2004) : "Plasma manganese, selenium, zinc, copper, and iron concentrations in patients with schizophrenia". Biol. Trace Elem. Res., 98 (2): 109-117. 


\section{عستوى النحاس والزنك فى شعر كلا عن عرضى الفصام والاكتئاب}

$$
\text { المشتركون فى البحث }
$$

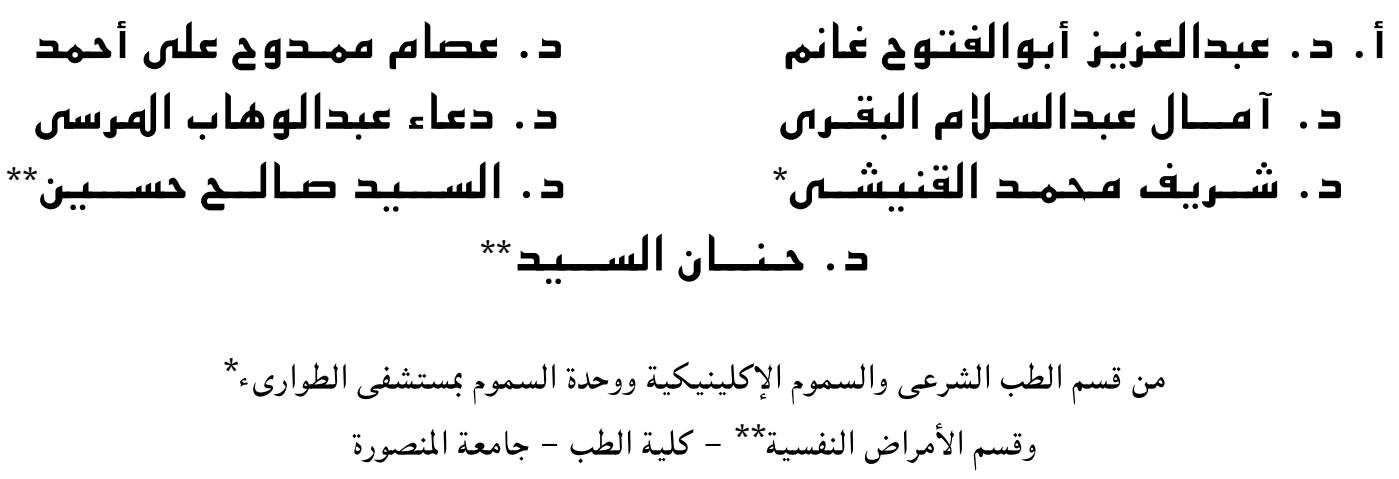

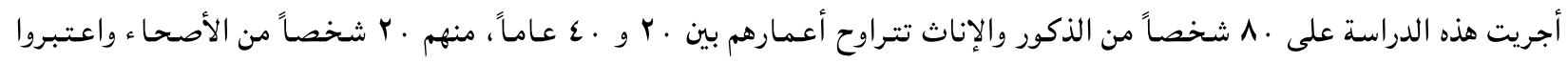

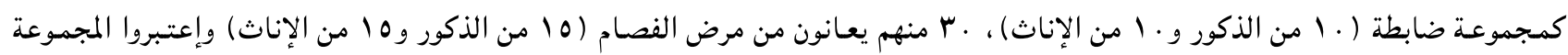

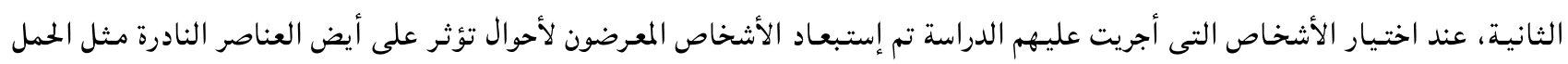

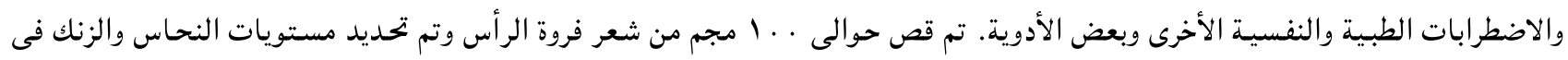

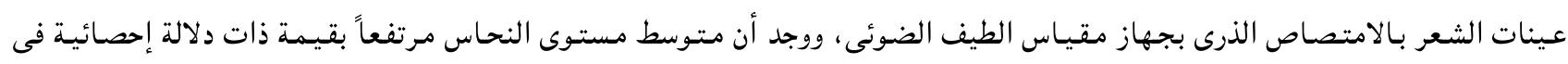

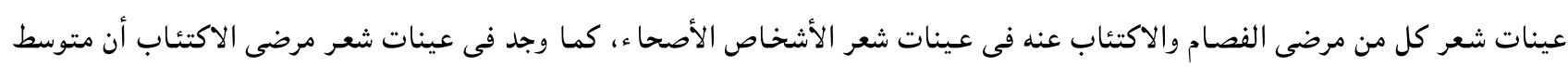

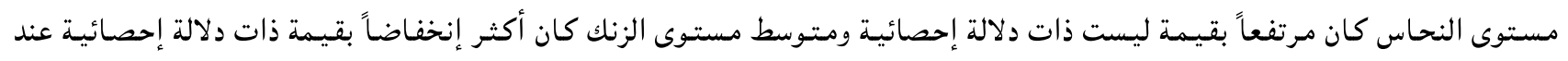
مقارنتهم بتوسط مستويات النحاس والزنك فى شعر مرضى الفصام.

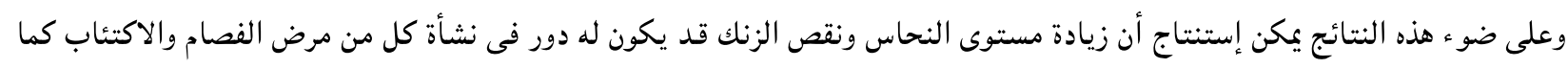

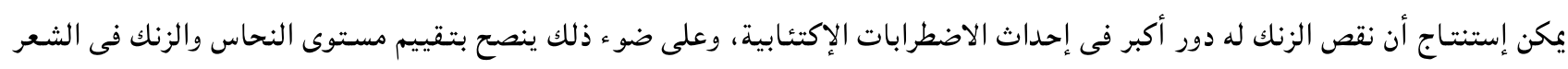

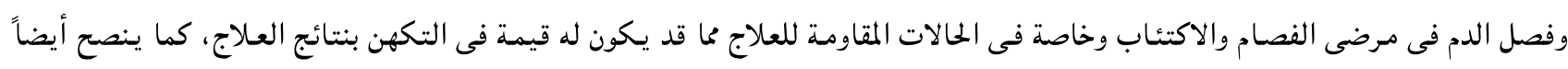

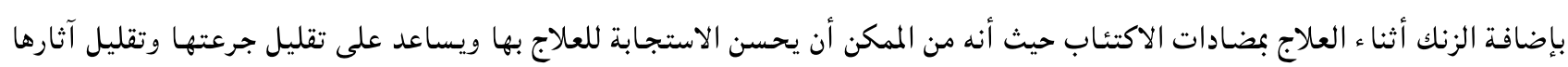
الجانبية. 